\title{
Isothiocyanate-induced Cell Cycle Arrest in a Novel In Vitro Exposure Protocol of Human Malignant Melanoma (A375) Cells
}

\author{
THEODORA MANTSO ${ }^{1}$, IOANNIS ANESTOPOULOS ${ }^{2}$, ELEFTHERIA LAMPRIANIDOU ${ }^{3}$, \\ IOANNIS KOTSIANIDIS ${ }^{3}$, AGLAIA PAPPA ${ }^{2}$ and MIHALIS I. PANAYIOTIDIS ${ }^{1}$ \\ ${ }^{1}$ Department of Applied Sciences, Northumbria University, Newcastle Upon Tyne, U.K.; \\ ${ }^{2}$ Department of Molecular Biology and Genetics, Democritus University of Thrace, Alexandroupolis, Greece; \\ ${ }^{3}$ Department of Hematology, School of Medicine, Democritus University of Thrace, Alexandroupolis, Greece
}

\begin{abstract}
Background/Aim: Several studies have documented the effects of isothiocyanates (ITCs) on cancer prevention by inducing oxidative stress, activating apoptosis, affecting cellcycle regulation, etc. Previously, we have shown that ITCs, administered at low concentrations by the means of doublebolus are capable of potentiating cytotoxicity in human malignant melanoma (A375) cells by inducing apoptosis. The aim of the present study was to further investigate the effect of the treatment of A375 cells with ITCs on cell-cycle progression and the levels of various cell cycle regulators. Materials and Methods: Cell-cycle analysis was performed by means of flow cytometry whereas western immunoblotting was used to determine the expression levels of these protein regulators. Results: Our data showed an increase in the number of cells in the $G_{2} / M$ phase accompanied by a decrease in the $G_{0} / G_{1}$ phase, while several cell-cycle regulators were shown to be differentially expressed upon exposure to ITCs. Conclusion: ITCs induced cell-cycle arrest in A375 cells.
\end{abstract}

Malignant melanoma is the most aggressive and lethal form of skin cancer due to its high mortality and continuously increasing incidence rates $(1,2)$. On the other hand, consumption of cruciferous vegetables has been suggested to play a beneficial role in cancer prevention. Their anti-cancer effects appear to be attributed to isothiocyanates (ITCs), a group of compounds derived from the hydrolysis of glucosinolates (GSLs) which are sulfur- and nitrogencontaining glycosides, by the enzyme myrosinase (3-6). In

Correspondence to: Professor Mihalis I. Panayiotidis, Ph.D., Department of Applied Sciences, Group of Translational Biosciences, Faculty of Health \& Life Sciences, Northumbria University, Ellison Building A516, Newcastle Upon Tyne, NE1 8ST, U.K. Tel: +44 01912274503, e-mail: m.panagiotidis@northumbria.ac.uk

Key Words: Isothiocyanates, malignant melanoma, A375 cells, cell cycle, growth arrest. recent years, various studies have focused on investigating the diverse pathways induced by ITCs including (i) activation of phase I and II detoxification, (ii) generation of oxidative stress, (iii) induction of cell-cycle growth arrest and apoptosis, (iv) inhibition of tumor cell invasion, metastasis and angiogenesis, (v) suppression of inflammatory response and (vi) regulation of epigenetic cascades (7-11). To this end, we have previously published on the ability of different ITCs (e.g. sulforaphane, SFN; phenethyl isothiocyanate, PEITC; and benzyl isothiocyanate, BITC) to trigger apoptosis in human malignant melanoma (A375) cells by utilizing a previously published means of administering low concentrations of ITCs as a refreshed double-bolus (12). This study aimed to investigate further the effects of ITCs on the cell cycle, as an additional mechanism contributing to the cytotoxicity observed in our previous study in A375 cells.

\section{Materials and Methods}

Chemicals and reagents. Dulbecco's Modified Eagle Media (DMEM), Phosphate Buffer Saline (PBS), Fetal Bovine Serum (FBS), trypsin, penicillin/streptomycin and L-glutamine were obtained from Labtech (Sussex, UK). Bovine Serum Albumin (BSA) was purchased from Biosera (Boussens, France). Polyvinylidene Difluoride (PVDF) membranes, page ruler plus protein marker, ECL and FxCycle PI/RNase staining solution were supplied by Thermo Fisher Scientific (Waltham, MA, USA). All primary and horseradish peroxidase-conjugated secondary antibodies were purchased from Cell Signaling (Danvers, MA, USA) apart from $\beta$-actin (Sigma-Aldrich; St. Louis, MO, USA). SFN was purchased from Abcam (Cambridge, UK) while PEITC and BITC from Sigma-Aldrich. Stock solutions were prepared in DMSO (Sigma-Aldrich) at $100 \mathrm{mM}$ and stored at $-20^{\circ} \mathrm{C}$. All chemicals were of analytical grade and obtained from Invitrogen (Carlsbad, CA, USA), Applichem (Darmstadt, Germany) and Sigma-Aldrich.

Cell lines and treatments with isothiocyanates. The A375 cell line was purchased from Sigma-Aldrich and maintained in high glucose DMEM supplemented with $10 \%$ FBS, 2 mM L-glutamine and $1 \%$ pen/strep (100 U/ml penicillin, $100 \mu \mathrm{g} / \mathrm{ml}$ streptomycin). Cells were 
cultured in a humidified atmosphere at $37^{\circ} \mathrm{C}$ and $5 \% \mathrm{CO}_{2}$. They were grown as monolayer cultures and sub-cultured when reaching $80-90 \%$ confluence. SFN, PEITC and BITC were added twice as a refreshed bolus concentration of $5 \mu \mathrm{M}$ (each added at t0 and refreshed after $24 \mathrm{~h}$ ) over a 48 -h incubation period.

Protein extraction and quantification. Cells were treated with $5 \mu \mathrm{M}$ of ITC or vehicle (for $48 \mathrm{~h}$ ), harvested via trypsinization, washed twice with cold PBS and then stored at $-20^{\circ} \mathrm{C}$. Cell pellets were lysed in lysis buffer (10 mM HEPES pH 7.9, $10 \mathrm{mM} \mathrm{KCl}, 0.1 \mathrm{mM}$ EDTA, $\left.1.5 \mathrm{mM} \mathrm{MgCl}_{2}, 0.2 \% \mathrm{NP}-40\right)$ supplemented with protease inhibitors. Samples were incubated on ice while periodically vortexed over a $30 \mathrm{~min}$ period. Cell lysates were centrifuged $(14,000 \times g)$ at $4^{\circ} \mathrm{C}$ for $15 \mathrm{~min}$ and supernatants were collected. Protein concentration was determined by the BCA assay (Thermo Fisher Scientific) according to the manufacturer's protocol. Protein extracts were stored at $-20^{\circ} \mathrm{C}$ until usage.

Western immunoblotting. Proteins $(40 \mu \mathrm{g})$ were separated by using gradient SDS-polyacrylamide gels $(8-20 \%)$ and then were transferred onto either 0.2 or $0.45 \mu \mathrm{m}$ PVDF membranes (depending on their molecular weight) by wet transfer (in $1 X$ transfer buffer) at predetermined running conditions. The blots were blocked with $5 \%$ (w/v) non-fat milk powder in Tris Buffered Saline, with Tween 20 (TBST) buffer, for $1 \mathrm{~h}$ at room temperature (RT) and then incubated with specific primary antibodies (overnight at $4^{\circ} \mathrm{C}$ ) under gentle agitation. Next day, the blots were washed (three times) in TBST buffer for $10 \mathrm{~min}$ and then incubated with an appropriate secondary antibody (for $1 \mathrm{~h}$ at RT) under agitation. Blots were incubated with the super signal west pico chemiluminescent substrate (Thermo Fisher Scientific) according to the manufacturer's instructions before being imaged by using a ChemiDoc $\mathrm{XRS}^{+}$system (Bio-Rad, Perth, UK).

Cell cycle analysis by flow cytometry. Cells were treated with $5 \mu \mathrm{M}$ of ITC or vehicle (for $48 \mathrm{~h}$ ), harvested via trypsinization and washed twice with PBS. Then, cells $\left(0.5 \times 10^{6}\right)$ were fixed in cold $70 \%$ ethanol (for $1 \mathrm{~h}$ ) at $4^{\circ} \mathrm{C}$ until further processed. Cells were washed twice with PBS to remove ethanol, and then were suspended in FxCycle PI/RNase staining solution for $30 \mathrm{~min}$ (at RT) in dark. Samples were analyzed by FACS Calibur Flow Cytometer (BD Biosciences) with 10,000 events being recorded under each condition and analyzed using the FlowJo V10 software (BD Biosciences)

Statistical analysis. Statistical analyses were performed by one-way ANOVA with Tukey's test for multiple comparisons after using the SPSS v.22 software. Statistical significance was set at $p<0.05$.

\section{Results}

Human malignant melanoma (A375) cells were exposed to a refreshed, double-bolus low concentration $(5 \mu \mathrm{M})$ of SFN, PEITC or BITC according to our previous findings (12). Determination of the distribution of cells to cell-cycle phases by flow cytometry, revealed an induction of the $\mathrm{G}_{2} / \mathrm{M}$ cell cycle phase by all ITCs (Figure 1A and B). Exposure to BITC induced the highest increase in the number of cells in the $\mathrm{G}_{2} / \mathrm{M}$ phase followed by SFN and PEITC which had the same effect. This pattern was followed by a reduction in the number of cells in the $G_{0} / G_{1}$ phase, by all three ITCs, while only BITC induced a significant change in the number of cells in the $\mathrm{S}$ phase of the cell cycle (Figure 1A and B). Finally, our data showed a profound elevation, to a variable degree, in the percentage of cells in the sub- $\mathrm{G}_{1}$ phase (which accounts for a necrotic and/or apoptotic cell population) by all three ITCs (Figure 1A and B). The underlying mechanism(s) contributing to the observed induction of cell-cycle growth arrest in A375 cells was examined by monitoring alterations in expression levels of various cell cycle protein regulators. According to our results, the levels of cyclin dependent kinase inhibitors p21 and p27 as well as phospho-p53 (Ser15) were upregulated in contrast to those of $\mathrm{p} 18$ which were markedly reduced (Figure 2A). Furthermore, the levels of cyclins D1 and D3 were increased independently of the type of ITC utilized (Figure 2B). In addition, cyclin-dependent kinase 6 (CDK6) was shown to decrease while cyclin-dependent kinase 2 (CDK2) significantly increased in response to ITCs exposure. Finally, the protein expression levels of cyclindependent kinase 4 (CDK4) were shown to be up-regulated, in the case of SFN and PEITC, as opposed to exposure to BITC, which caused a marked reduction (Figure 2C). Overall, our data highlight the involvement of various cell cycleregulating proteins in inducing cell cycle arrest as a consequence of the exposure of A375 cells to low-ITC concentrations administered as refreshed, double-bolus (12).

\section{Discussion}

Our findings revealed an increase in the number of cells in the $G_{2} / M$ phase accompanied by a decrease in the number of cells in the $G_{0} / G_{1}$ phase following exposure of A375 cells to ITCs. Furthermore, a reduction in the $\mathrm{S}$ phase population was also observed but only after BITC exposure. Moreover, in agreement with our previous findings of ITC-induced apoptosis in A375 cells, a profound elevation in the percentage of cells in the sub- $\mathrm{G}_{1}$ phase fraction was detected $(12,13)$. However, it is of significance to note that the levels of cytotoxicity were comparable with those in other experimental platforms using rather higher concentrations of ITCs, administered as a single bolus (14-18). In order to study the mechanism of action of ITCs, the expression levels of various cell cycle regulators were examined. Treatment with ITCs resulted in an induction of p21 and p27 expression levels, a finding consistent with the role of both proteins in binding to cyclin-CDK complexes and thus suppressing cell cycle progression (19). In support, several studies have demonstrated the ITC-induced up-regulation of p21 in various human cancer cell lines $(20,21)$. Similarly, increased p27 expression has been documented in both in vitro and in vivo models treated with various ITCs $(22,23)$. In addition, the levels of phospho-p53 (Ser15) protein were also found to be upregulated. This finding is in accordance with the 

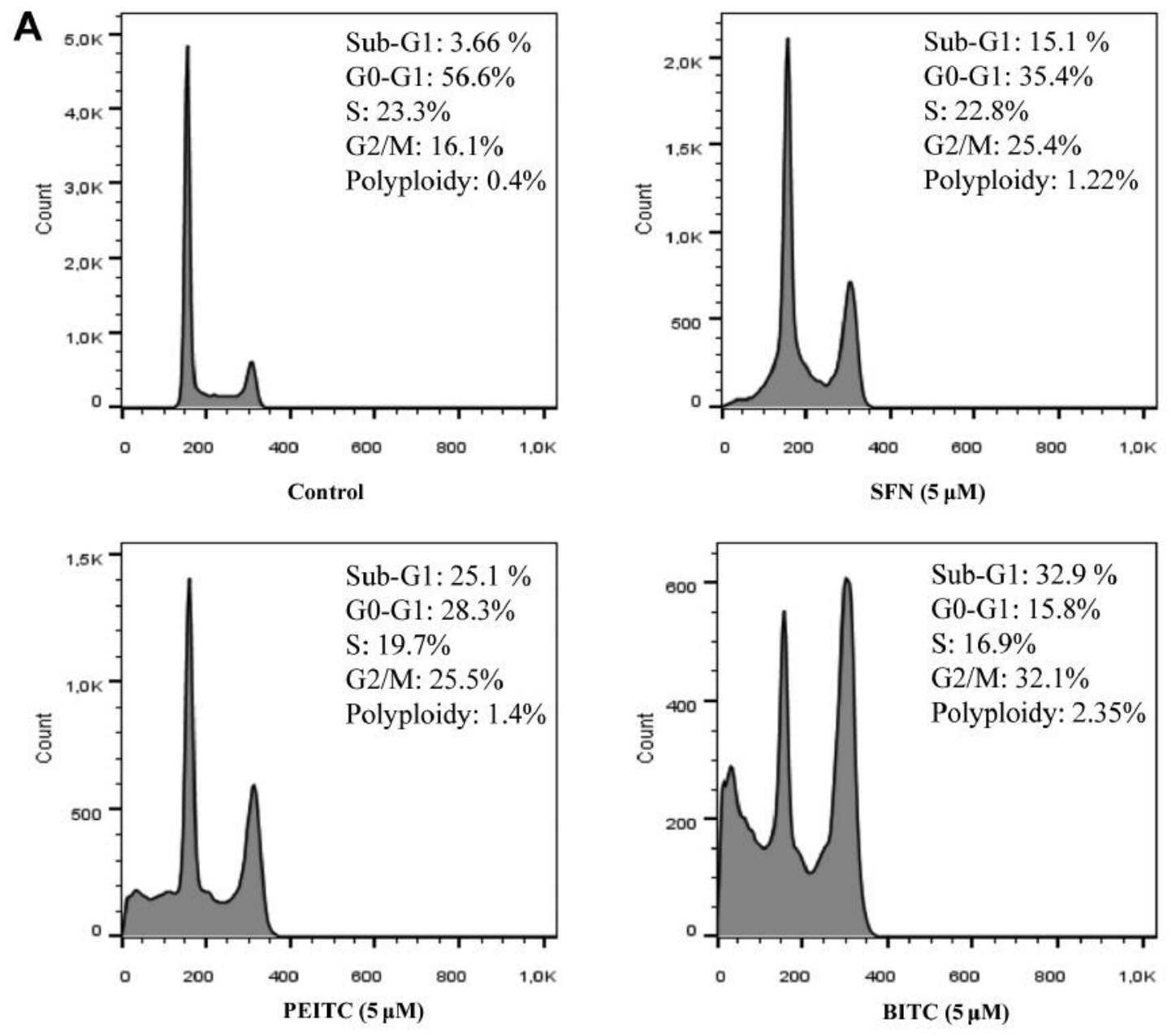

B

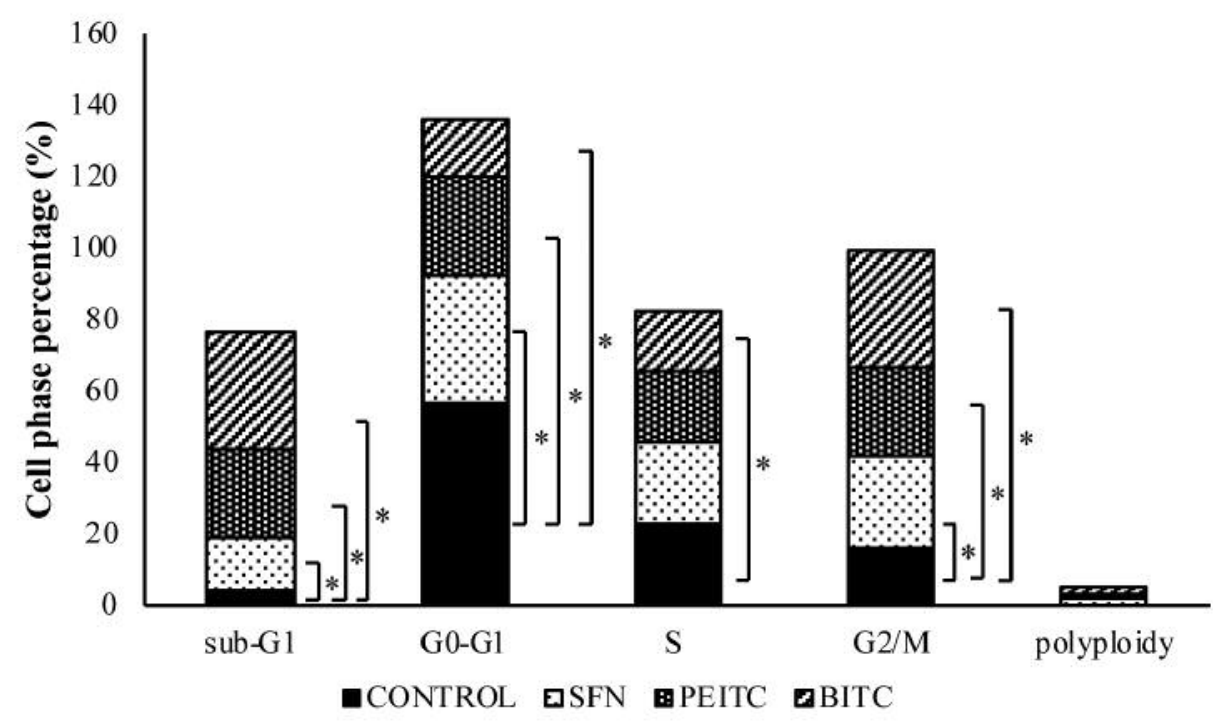

Figure 1. The effect of ITCs exposure on the distribution of human malignant melanoma (A375) cells in cell-cycle phases. (A) Representative histograms of the distribution of cells in cell-cycle phases following exposure to $5 \mu \mathrm{M}$ of SFN, PEITC or BITC for an initial 24 h after which exposures were refreshed for a further $24 \mathrm{~h}$ incubation (for a total exposure period of $48 \mathrm{~h}$ ). (B) Diagram showing the distribution of cells in sub-G $, G_{0} / G_{l}, S, G_{2} / M$ cell-cycle phases and polyploidy. Results are expressed as percentage of total cells and mean $\pm S D$ were calculated. Asterisk $(*)$ indicates statistical significance at $p<0.05$ when compared to control. Brackets denote comparisons between each cell-cycle phase under each individual ITC exposure. 


\section{A Control SFN PEITC BITC}
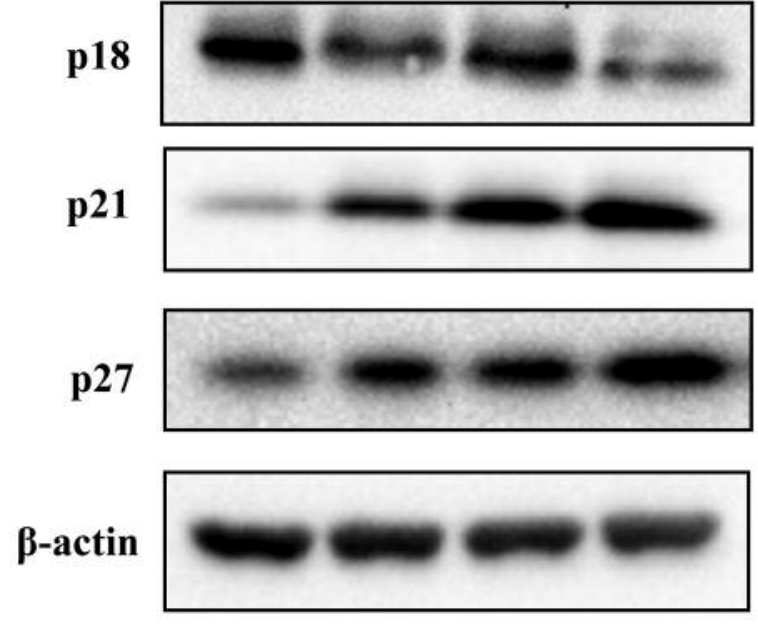

B Control SFN PEITC BITC
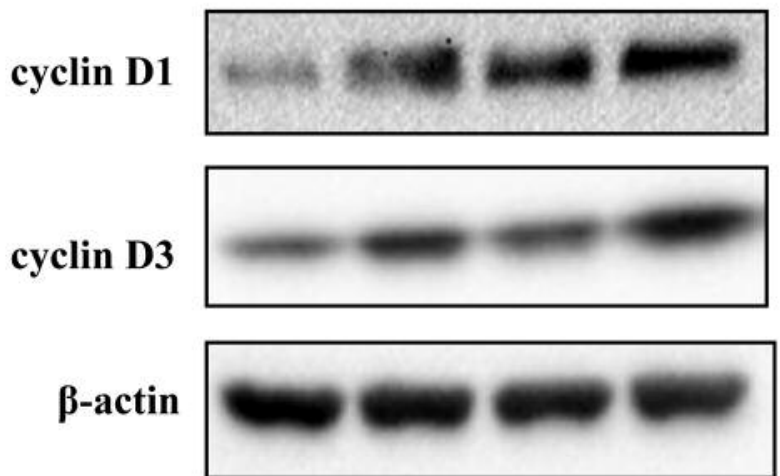

\section{Control SFN PEITC BITC}
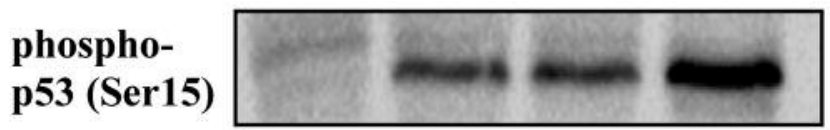

$\beta$-actin

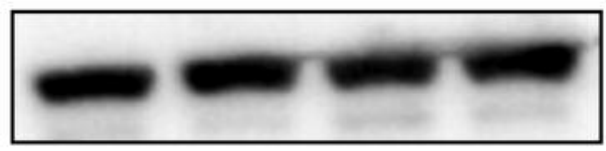

C Control SFN PEITC BITC

CDK2

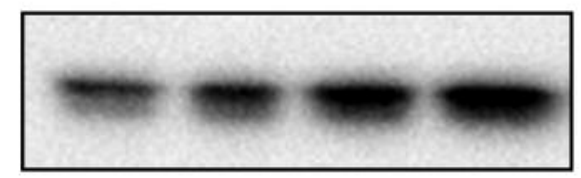

CDK4

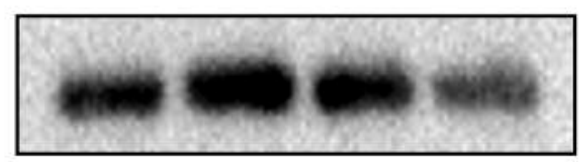

CDK6

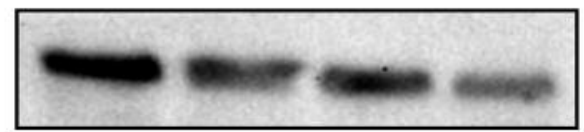

$\beta$-actin

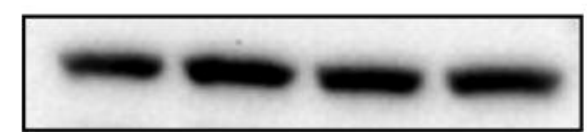

Figure 2. The effect of ITCs on the levels of various cell-cycle regulators in human malignant melanoma (A375) cells. A375 cells were exposed to $5 \mu M$ of SFN, PEITC or BITC for an initial $24 \mathrm{~h}$ after which exposures were refreshed for a further $24 \mathrm{~h}$ incubation (for a total exposure period of 48 h). Cell extracts were analysed by western blot using antibodies against p18, p21, p27 and phospho-p53 (Ser15) (A), cyclins D1 and D3 (B) and cyclin dependent kinases 2,4 , and $6(C) \beta$-actin was used as a loading control.

findings of other studies showing that ITC-induced apoptosis is associated with p53 up-regulation in melanoma cells (16, 24). On the contrary, a reduction in p18 levels (more evident in BITC exposure) was observed. This effect can be attributed to the interaction of this protein with CDK4 and CDK6 resulting in their inhibition and consequently cell cycle halt (25). Furthermore, increased levels of CDK2 (under exposure to each ITC) were also observed suggesting its interaction with cyclin $\mathrm{E}$ which may lead to cell-cycle progression and/or apoptotic induction $(26,27)$. Finally, when examining expression levels of cyclins D1 and D3, it was apparent that both proteins were up-regulated in response to each ITC exposure. These findings are also consistent with those of other studies where exposure of melanoma cells to ITCs was shown to be associated with the constitutive activation of the BRAF-MEK-ERK $1 / 2$ cascade as well as cell cycle progression $(28,29)$. Overall, the present study provides further evidence in support of our previously published means of treatment with ITCs in the context of halting cell-cycle progression by affecting the expression of several cell-cycle regulators in human malignant melanoma (A375) cells. These observations, along 
with our previously published apoptotic induction, highlight the importance of this novel means of delivering low-ITC concentrations as refreshed, double-bolus as a more efficient and potent therapeutic strategy against malignant melanoma.

\section{Authors' Contributions}

Conceptualization, M.I.P.; methodology, T.M., E.L., I.K., M.I.P.; analysis, T.M., I.A., E.L., I.K., A.P., M.I.P.; investigation, T.M., I.A., E.L.; resources, A.P., I.K., M.I.P.; writing-original draft preparation, T.M., M.I.P.; writing-review and editing, T.M., I.A., E.L., I.K., A.P., M.I.P.; supervision, M.I.P.; funding acquisition, A.P., M.I.P.

\section{Conflicts of Interest}

The Authors declare no competing financial interests regarding this study.

\section{Acknowledgements}

This work was supported by (i) start-up funds from the Multidisciplinary Research Theme (MDRT) in Bio-economy at Northumbria University, Newcastle Upon Tyne, UK (M.I.P); (ii) an LLP Erasmus Program (AP) and (iii) an "OPENSCREEN-GR: An Open-Access Research Infrastructure of Target-Based Screening Technologies and Chemical Biology for Human \& Animal Health, Agriculture \& Environment (MIS 5002691)" implemented under the action "Reinforcement of the Research and Innovation Infrastructure" funded by the Operational Program "Competitiveness, Entrepreneurship and Innovation (NSRF 2014-2020)" co-financed by Greece and the European Union (under the European Regional Development Fund) (AP). The Authors would like to thank Dr. Eleni Fitsiou for her technical support in flow cytometry experiments.

\section{References}

1 Arnold M, Holterhues C, Hollestein LM, Coebergh JW, Nijsten T, Pukkala E, Holleczek B, Tryggvadóttir L, Comber H, Bento MJ, Diba ChS, Micallef R, Primic-Žakelj M, Izarzugaza MI, Perucha J, Marcos-Gragera R, Galceran J, Ardanaz E, Schaffar $\mathrm{R}$, Pring A and de Vries E: Trends in incidence and predictions of cutaneous melanoma across Europe up to 2015. J Eur Acad Dermatol Venereol 28(9): 1170-1178, 2014.

2 Hunter HL, Dolan OM, McMullen E, Donnelly D and Gavin A: Incidence and survival in patients with cutaneous malignant melanoma: experience in a U.K. population, 1984-2009. Br J Dermatol 168(3): 676-678, 2013.

3 Abdull Razis AF and Noor NM: Cruciferous vegetables: dietary phytochemicals for cancer prevention. Asian Pac J Cancer Prev 14(3): 1565-1570, 2013.

4 Tse G and Eslick GD: Cruciferous vegetables and risk of colorectal neoplasms: a systematic review and meta-analysis. Nutr Cancer 66(1): 128-139, 2014.

5 Watson GW, Beaver ML, Williams DE, Dashwood RH and Ho E: Phytochemicals from cruciferous vegetables, epigenetics and prostate cancer prevention. AAPS J 15(4): 951-961, 2013.

6 Halkier BA and Gershenzon J: Biology and biochemistry of glucosinolates. Annu Rev Plant Biol 57: 303-333, 2006.
7 Navarro SL, Li F and Lampe JW: Mechanisms of action of isothiocyanates in cancer chemoprevention: an update. Food Funct 2(10): 579-587, 2011.

8 Dinkova-Kostova AT and Kostov RV: Glucosinolates and isothiocyanates in health and disease. Trends Mol Med 18(6): 337-347, 2012.

9 Romeo L, Iori R, Rollin P, Bramanti P and Mazzon E: Isothiocyanates: An overview of their antimicrobial activity against human infections. Molecules 23(3): E624, 2018.

10 Fofaria NM, Ranjan A, Kim SH and Srivastava SK: Mechanisms of the Anticancer Effects of Isothiocyanates. Enzymes 37: 111$137,2015$.

11 Mitsiogianni M, Amery T, Franco R, Zoumpourlis V, Pappa A and Panayiotidis MI: From chemo-prevention to epigenetic regulation: The role of isothiocyanates in skin cancer prevention. Pharmacol Ther 190: 187-201, 2018.

12 Mantso T, Sfakianos AP, Atkinson A, Anestopoulos I, Mitsiogianni M, Botaitis S, Perente S, Simopoulos C, Vasileiadis. S, Franco R, Pappa A and Panayiotidis. MI: Development of a novel experimental in vitro model of isothiocyanate-induced apoptosis in human malignant melanoma cells. Anticancer Res 36(12): 6303-6309, 2016.

13 Crowley LC, Chojnowski G and Waterhouse NJ: Measuring the DNA content of cells in apoptosis and at different cell-cycle stages by propidium iodide staining and flow cytometry. Cold Spring Harb Protoc 2016(10): 2016. doi: 10.1101/ pdb.prot087247.

14 Sharma AK, Sharma A, Desai D, Madhunapantula SV, Huh SJ, Robertson GP and Amin S: Synthesis and anticancer activity comparison of phenylalkyl isoselenocyanates with corresponding naturally occurring and synthetic isothiocyanates. J Med Chem 51(24): 7820-7826, 2008.

15 Huang SH, Wu LW, Huang AC, Yu CC, Lian JC, Huang YP, Yang JS, Yang JH, Hsiao YP, Wood WG, Yu CS and Chung JG: Benzyl isothiocyanate (BITC) induces $\mathrm{G}_{2} / \mathrm{M}$ phase arrest and apoptosis in human melanoma A375.S2 cells through reactive oxygen species (ROS) and both mitochondria-dependent and death receptor-mediated multiple signaling pathways. J Agric Food Chem 60(2): 665-675, 2012.

16 Rudolf K, Cervinka M and Rudolf E: Sulforaphane-induced apoptosis involves p53 and p38 in melanoma cells. Apoptosis 19(4): 734-747, 2014.

17 Arcidiacono P, Ragonese F, Stabile A, Pistilli A, Kuligina E, Rende M, Bottoni U, Calvieri S, Crisanti A and Spaccapelo R: Antitumor activity and expression profiles of genes induced by sulforaphane in human melanoma cells. Eur J Nutr 57(7): 25472569, 2017.

18 Huang SH, Hsu MH, Hsu SC, Yang JS, Huang WW, Huang AC, Hsiao YP, Yu CC and Chung JG: Phenethyl isothiocyanate triggers apoptosis in human malignant melanoma A375.S2 cells through reactive oxygen species and the mitochondria-dependent pathways. Hum Exp Toxicol 33(3): 270-283, 2014.

19 Coqueret O: New roles for p21 and p27 cell-cycle inhibitors: a function for each cell compartment? Trends Cell Biol 13(2): 65$70,2003$.

20 Żuryń A, Litwiniec A, Safiejko-Mroczka B, KlimaszewskaWiśniewska A, Gagat M, Krajewski A, Gackowska L and Grzanka D: The effect of sulforaphane on the cell cycle, apoptosis and expression of cyclin D1 and p21 in the A549 non-small cell lung cancer cell line. Int J Oncol 48(6): 2521-2533, 2016. 
21 Yeh YT, Yeh H, Su SH, Lin JS, Lee KJ, Shyu HW, Chen ZF, Huang SY and Su SJ: Phenethyl isothiocyanate induces DNA damage-associated G2/M arrest and subsequent apoptosis in oral cancer cells with varying p53 mutations. Free Radic Biol Med 74: 1-13, 2014.

22 Chung YK, Chi-Hung Or R, Lu CH, Ouyang WT, Yang SY and Chang CC: Sulforaphane down-regulates SKP2 to stabilize p27(KIP1) for inducing antiproliferation in human colon adenocarcinoma cells. J Biosci Bioeng 119(1): 35-42, 2015.

23 Boreddy SR, Pramanik KC and Srivastava SK: Pancreatic tumor suppression by benzyl isothiocyanate is associated with inhibition of PI3K/AKT/FOXO pathway. Clin Cancer Res 17(7): 1784-1795, 2011.

24 Hamsa TP, Thejass P and Kuttan G: Induction of apoptosis by sulforaphane in highly metastatic B16F-10 melanoma cells. Drug Chem Toxicol 34(3): 332-340, 2011.

25 Noh SJ, Li Y, Xiong Y and Guan KL: Identification of functional elements of p18INK4C essential for binding and inhibition of cyclin-dependent kinase (CDK) 4 and CDK6. Cancer Res 59(3): 558-564, 1999.

26 Gladden AB and Diehl JA: Cell cycle progression without cyclin E/CDK2: breaking down the walls of dogma. Cancer Cell 4(3): 160-162, 2003.
27 Choi JS, Shin S, Jin YH, Yim H, Koo KT, Chun KH, Oh YT, Lee WH and Lee SK: Cyclin-dependent protein kinase 2 activity is required for mitochondrial translocation of Bax and disruption of mitochondrial transmembrane potential during etoposideinduced apoptosis. Apoptosis 12(7): 1229-1241, 2007.

28 Bhatt KV, Spoffold LS, Aram G, McMullen M, Pumiglia K and Aplin AE: Adhesion control of cyclin D1 and p27Kip1 levels is deregulated in melanoma cells through BRAF-MEK-ERK signaling. Oncogene 24(21): 3459-3471, 2005.

29 Spofford LS, Abel EV, Boisvert-Adamo K and Aplin AE: Cyclin D3 expression in melanoma cells is regulated by adhesiondependent phosphatidylinositol 3-kinase signaling and contributes to $\mathrm{G}_{1}-\mathrm{S}$ progression. J Biol Chem 281(35): 25644-25651, 2006.

Received December 18, 2018

Revised January 4, 2019

Accepted January 7, 2019 